\title{
The Psychological Effects on IT Professionals During COVID-19 in the United States and Internationally
}

\author{
Dhanya Janga, Tanishka Aglave \\ John F. Kennedy Memorial High School, 200 Washington Ave, Iselin, NJ, 08830, U.S.A.; djanga040@gmail.com
}

ABSTRACT: The mental health of IT professionals in the corporate world has been an increasing concern during the lockdown of the Coronavirus pandemic. The current circumstances societies face have thrown this fragile demographic back into the spotlight. This study aims to conduct a timely assessment of the effects of the COVID-19 pandemic on the mental health of IT professionals within the United States and as well as the rest of the world. To help understand the impact of the pandemic on IT professionals' mental health and well-being, interviews with 64 IT employees were within the United States and 21 interviews with international IT employees were conducted. Quantitative and qualitative approaches were used to interpret the results.

KEYWORDS: COVID-19; pandemic; IT professionals; mental health.

\section{- Introduction}

Business in the IT world is often hampered by mental health problems. Mental health disorders may affect IT professional's motivation, attention, and social experiences, all of which are critical in business in the IT world. According to the US Bureau of Labor Statistics, the year started with a bang for IT workers, with 25,300 tech workers added to U.S. payrolls in the first two months (BLS). However, by March, this figure had fallen to just 6,000 new IT workers, and by April, the BLS had recorded a staggering net loss of 181,300 tech jobs in the United States. ${ }^{1}$ Joe Pinker's (2020) Atlantic post, "The Pandemic will cleave America in Two," highlights two contrasting pandemic perspectives. ${ }^{2}$ One is an insight shared by those with advanced degrees who work in stable occupations that allow for telework. People's lives have become more complicated, their jobs have been turned upside down, childcare has been difficult, and leaving the house feels ominous. The other is an experience shared with the majority of the working population - those who are unable to work at home and therefore put themselves in danger every day, whose careers have been lost or downsized, and who are concerned not just about contracting the virus but also about having the opportunity and money to survive. ${ }^{3}$ Internationally COVID-19 had many effects on the employee's mental health in the IT industry well. Many workers either lost their jobs or had their salaries reduced. The unemployment rate has risen in all global economies. ${ }^{3}$ According to the International Monetary Fund (IMF), the number of workers out of jobs in the United States reached an all-time high of $8.9 \%$ last year, marking the end of a decade of employment growth. When sectors of the economy, such as tourism and hospitality, have come to a halt, millions of jobs have been put on government-sponsored job relation programs. In many countries, the amount of new career openings is still very limited. Job openings in Australia have returned to the same number as in 2019, but in France, Spain, the United Kingdom, and many other nations, they are still falling short. ${ }^{5}$
This is affecting the mental health of people. No employment is equal to no money which clearly brings up a lot of problems.

Information technology is one of the biggest industries in the world with considerable employment. The IT industry plays a vital role in managing other businesses, exchanging information, and developing technology for everyday lives. Apart from this, many IT professionals have families of their own to tend to. The pandemic has posed many challenges adding additional stressors to many IT employees. The pandemic has caused mental health concerns to skyrocket, and this survey will focus on IT professionals' mental health to learn how one of the biggest job sectors worldwide had been influenced by the Covid-19 pandemic.

\section{Methods.}

Study Design :

A semi-structured interview survey guide was created with the aim of quantitative and qualitatively measuring the mental health status of IT professionals. In addition, the interview was designed to learn about how IT professionals have dealt with the stress of the pandemic situation. The survey consisted of questions pertaining to IT professionals' daily habits, changes in their mental health, work ethics, screen time, how they dealt with the changes, and etc. The objective of this study is to assess the psychological changes that took place. The survey helped answer the essential question of this article: What are the psychological effects of COVID-19 on IT professionals' health in the US and internationally?

\section{- Results and Discussion. Data Collection :}

In this study, the effects of COVID-19 on both the employees who work in the United States as well as the employees who work in other countries were examined. First, participants were asked to answer from which state or country they are from. Most of the IT professionals were from the state of New Jersey and in the international survey, most of the participants were from India. Secondly, IT professionals were asked what designations they have in their company. The participants 
in the international survey were developers, administrators, and project managers. Others were testers, network engineers, operation workers, and technical architects. Most of the participants in the US survey were project managers, developers, business analysts, administrators, or worked in the quality department. Other participants were testers, worked in the production department, network engineers, operations, maintenance, architects, program managers, SAP consultants, product managers, lead engineers, system analysts, and worked in the construction department. The third question asked participants whether working from home affects productivity. This situation is becoming popular in the United States as the number of people working from home increases. Companies have been motivated to give workers the possibility of working from home as a result of the need for flexible working conditions and technological advancements. Furthermore, due to the coronavirus pandemic, many businesses have moved to an entirely remote workforce. According to a United States census bureau survey, $5.2 \%$ of full-time employees in the United States worked from home in 2017, up 3.3\% since 2000. To put that in context, there were 3.7 million people employed from home in 2000, up to 6.5 million today. In addition, the US Bureau of Labor Statistics estimated that $23.7 \%$ of Americans served from home for at least several hours in 2018. While studies to see how COVID-19 will impact these figures are underway, Global workplace analytics reports that $56 \%$ of the US population has a career that is at least partly consistent with remote jobs and that 25-30 percent of the workforce will be working from home for more than one day per week in the next two years. ${ }^{6}$ In this survey, most of the participants in the US have responded with a positive reply for the productivity of working from home. In an international IT professionals survey, responses from IT professionals were positive as well. Few responded that it had negative effects. The survey's fourth question was "do participants feel better working at home than working at an office?” The international survey participants' reply to this question was yes as well as no. Most of the participants said they feel better working at home than working in an office as there is no time limit and they can take their time to do the daily routine. Some of them said no because of the many distractions at home which led them not to be able to focus on work. In the US survey, participants' responses to this question were similar to those in the international survey. Their reasons for why they enjoyed working from home better was that there was no commute time, more flexibility, and people felt more relaxed. The participants who replied "no" enjoyed working in an office, working with people, working together. According to Sarah Archer's survey, 90\% of remote employees want to work from their homes for the remainder of their careers. $61 \%$ of workers have quit or considered quitting a workplace due to a lack of employment versatility. ${ }^{4}$

The fifth question of the survey related to some of the advantages of working from home. Respondents from the US survey replied that they have a flexible schedule, save money, zero commuting, no office distractions, it is easier to make calls, no need for formal clothes, more productivity, work, and
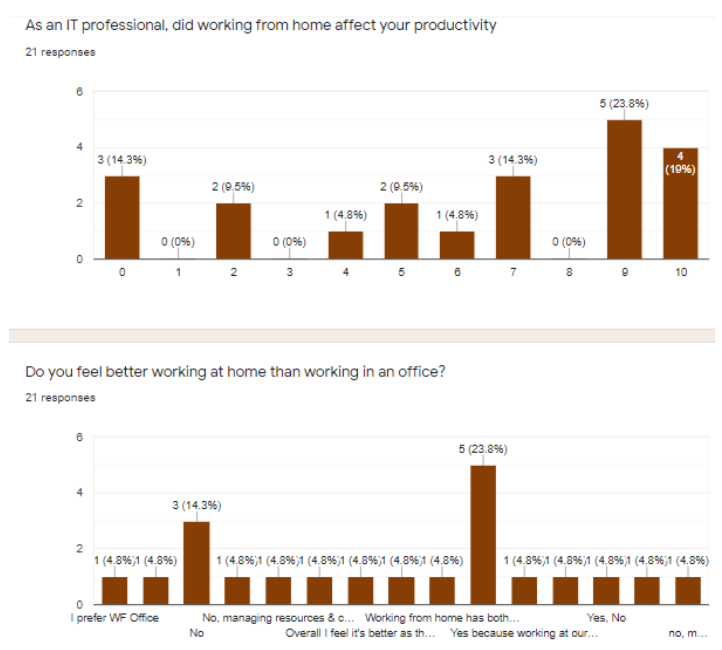

Figure 1: IT professionals were asked how working from home affected their productivity on a scale of 1-10 ( 1 being negatively and 10 resulting positively). Although responses varied, $70 \%$ of the employees reported an increased level of productivity.

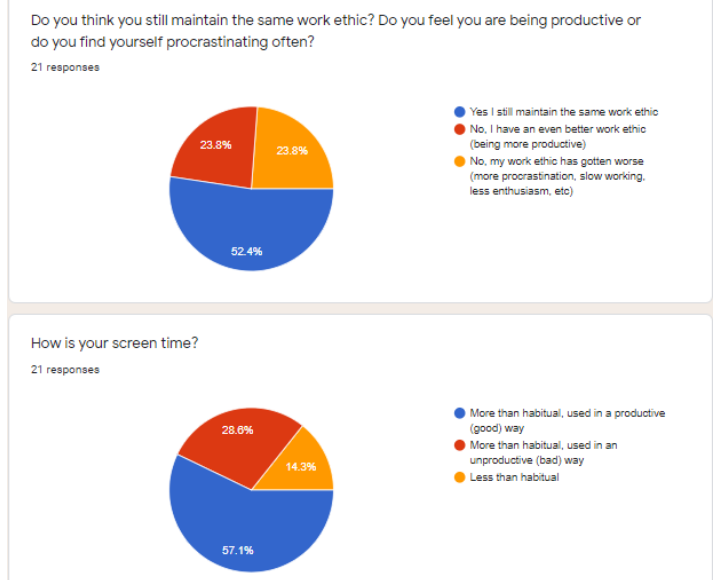

Figure 2: Participants were surveyed on their screen time as well as whether or not they maintained the same work ethic working from home. According to the graphs, more than $50 \%$ of IT professionals maintained the same work ethic prior to working from home and reported an increase in screen time.
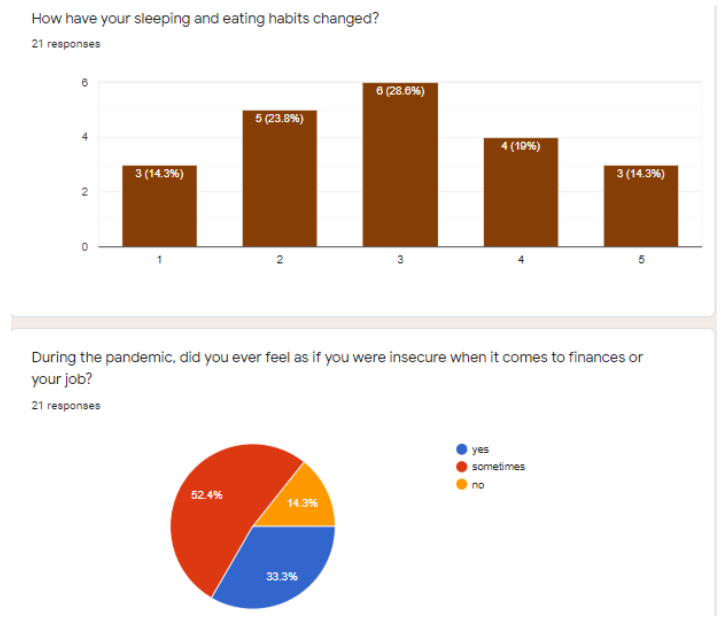

Figure 3: Candidates were also questioned about a change in eating/ sleeping habits as well as job insecurity. Since the majority of the respondents answered " 3 " on the scale it shows that their eating \& sleeping habits haven't significantly changed. In regard to job security, $86 \%$ of the IT professionals responded that they do feel insecure to some extent about jobs or finances. 


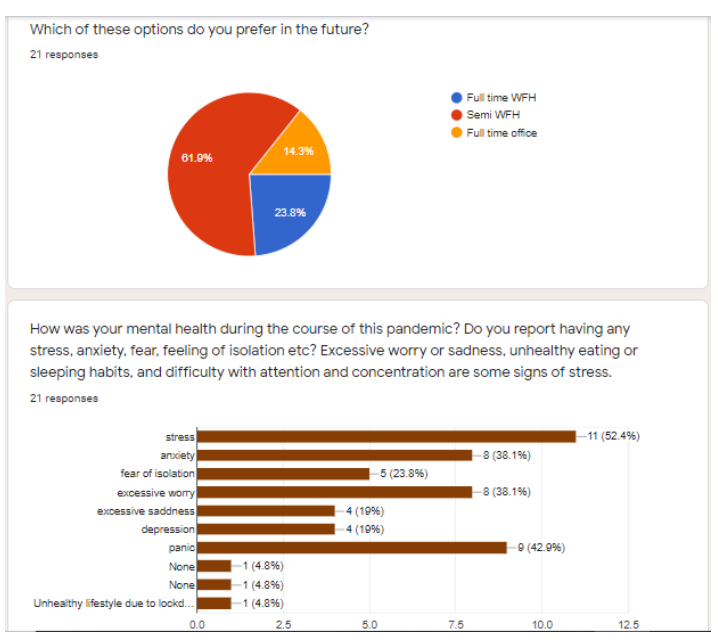

Figure 4: The graphs above show one of the most important aspects of this study: the mental health during the pandemic of IT professionals. They were also asked what work option they prefer for the future. More than half preferred semi-work from home for the future. Surrounding mental health concerns, workers reported increased levels of stress, anxiety, and excessive worries.

family balance, they get time to learn new things and less workload. Over $75 \%$ of the participants said they have a flexible schedule and $85.9 \%$ of the participants benefited from zero commuting. The next question asked was about the disadvantages of working from home. In the international survey, $57.1 \%$ of participants responded that there is difficulty or lack of communication, $42.9 \%$ of participants replied that there is difficulty in the working environment and motivational challenges, $38.1 \%$ of participants replied that there is difficulty in managing and maintaining accounts and loss of productivity. Some other disadvantages are ergonomic issues, and low reliability and retention. The disadvantages of working from home were a lack of community and differences in culture, difficulty or lack of communication, low reliability and retention, difficulty managing and maintaining accountability, issues with payment and logistics, loss of productivity, and security concerns. ${ }^{7}$ As seen from the survey responses, the participants' difficulties were similar to the disadvantages mentioned in the article. In the US survey, the responses of participants were quite similar to what they are in the international survey. Some other disadvantages mentioned by the participants were more working hours, no lunch break, and technical issues. According to the next question on how participants managed time and workflow, most participants in the international survey responded that they prioritize their work and do proper planning. In the US survey, most of the participants responded as they take frequent breaks, scheduling, proper planning, maintain a routine, sticking to the regular office routine, possess a dedicated office room, and other replies were similar to the one mentioned above (Figures 1 and 4). The eighth question to the participants was "do you think you still maintain the same work ethic? Do you feel you are being productive, or do you find yourself procrastinating often?" More than fifty percent of the participants that is $79.7 \%$ responded that "yes, I still maintain the same work ethic", $12.5 \%$ responded that "no, I have even better work ethic" (being more productive), been worsened i.e., more procrastination, slow working, and less enthusiasm (Figures 1 and 2).

\section{- Conclusion}

Working at home has been a challenge for many. Moreover, a global pandemic taking place is no way to lighten the load. "We are facing a health threat unlike any other in our lifetimes. Meanwhile, the virus is spreading, and day-to-day lives are being severely tested. Adapting to this new lifestyle can be difficult for some. This resulted in the mental health of IT professionals being challenged. This is a time for prudence, not panic". ${ }^{8}$ Everyone has been affected differently by the COVID-19 pandemic. Whether that be adjusting to a new work-life situation, the loss of a job, or a loved one, the weight of these unprecedented times can be heavy, and significantly impact our mental health. ${ }^{9}$ In terms of the data gathered, all results from the survey portray that there was indeed a negative effect of the pandemic on IT professionals' mental health. The dramatic changes encountered by all during the face of the pandemic, including changes in society and daily life, resulted in a severe mental health decline that included stress, anxiety, and even depression.

\section{Acknowledgements}

We would like to express our heartfelt gratitude to Dr. Balaji Aglave for constantly looking out for opportunities and platforms for us to present this project. We would also like to thank all the participants around the world who took part in this survey and made this research article possible.

\section{References}

1. U.S Bureau of Labor Statistics. Current employment statistics CES (National). https://www.bls.gov/ces/

(accessed Aug 16, 2021).

2. Pinsker, J. The pandemic WILL CLEAVE America in two. https:/www.theatlantic.com/family/archive/2020/04/ two-pandemics-us-coronavirus-inequality/609622/ (accessed Aug 16, 2021).

3. Blustein, D. L.; Duffy, R.; Ferreira, J. A.; Cohen-Scali, V.; Cinamon, R. G.; Allan, B. A. Unemployment in the Time of COVID-19: A Research Agenda. J. Vocat. Behav. 2020

4. Foote, D. How the pandemic is affecting tech jobs, skills and certifications. Insider Pro. 2020

5. Jones, B. L.; Brown, D. P. \&. Coronavirus: How the Pandemic Has Changed the World Economy. BBC. January 24, 2021.

6. 30+ work from home statistics https://www.yourbestdigs.com/ work-from-home-statistics/ (accessed Jun 17, 2021)

7. Go, R. 7 Disadvantages of Working from Home and How to Counter Them. Hubstaff.com, 2018.

8. COVID-19: We will come through this together https://www. un.org/sg/en/content/sg/articles/2020-03-16/covid-19-we-willcome-through-together (accessed Jun 17, 2021).

9. Mental health in the workplace during COVID-19: How can employers help? https://healthblog.uofmhealth.org/ wellness-prevention/mental-health-workplace-during-covid-19how-can-employers-help (accessed Jun 17, 2021).

10.Digital Class. Importance of information technology in today world - digital class. https://www.digitalclassworld.com/blog/ importance-of-information-technology/ (accessed Aug 2, 2021).

11.Giorgi, G.; Lecca, L. I.; Alessio, F.; Finstad, G. L.; Bondanini, G.; Lulli, L. G.; Arcangeli, G.; Mucci, N. Covid-19-related mental health effects in the workplace: A narrative review. https://www. ncbi.nlm.nih.gov/pmc/articles/PMC7663773/ (accessed Aug 2, 
2021).

12.Kamal, R. Both remote and on-site workers are grappling with serious mental health consequences of covid-19. https://www. kff.org/policy-watch/both-remote-and-on-site-workers-aregrappling-with-serious-mental- health-consequences-ofcovid-19/ (accessed Aug 2, 2021).

13.Foundation, N. I. H. C. M. COVID-19's impact on mental health and WORKPLACE WELL-BEING. https://nihcm. org/publications/covid-19s-impact-on-mental-health-andworkplace-well-being (accessed Aug 2, 2021).

\section{- Authors}

Dhanya Janga is a student at John F. Kennedy Memorial High School in Iselin, NJ. She has developed a passion for biomedical engineering and psychology through the research projects and literature reviews she has done. Dhanya has a keen interest in medicine and health sciences and aspires to work as a pediatrician in the future.

Tanishka Aglave is a student at Williams Middle Magnet School in Tampa, Florida. She has also developed an interest in science and STEM studies. One of her greatest accomplishments was winning first place at regional STEM competitions in Cellular and Molecular Biology. Her hobbies include volunteering at a community garden and a biology research lab. 